\title{
Electrophysiological correlates of automatic spreading of activation in patients with psychotic disorder and first-degree relatives
}

Citation for published version (APA):

Pfeifer, S., Schiller, N. O., van Os, J., Riedel, W. J., Vlamings, P., Simons, C., \& Krabbendam, L. (2012). Electrophysiological correlates of automatic spreading of activation in patients with psychotic disorder and first-degree relatives. International Journal of Psychophysiology, 84(1), 102-112. https://doi.org/10.1016/j.ijpsycho.2012.01.017

Document status and date:

Published: 01/04/2012

DOI:

10.1016/j.ijpsycho.2012.01.017

\section{Document license:}

Taverne

Please check the document version of this publication:

- A submitted manuscript is the version of the article upon submission and before peer-review. There can be important differences between the submitted version and the official published version of record.

People interested in the research are advised to contact the author for the final version of the publication, or visit the DOI to the publisher's website.

- The final author version and the galley proof are versions of the publication after peer review.

- The final published version features the final layout of the paper including the volume, issue and page numbers.

Link to publication

\footnotetext{
General rights rights.

- You may freely distribute the URL identifying the publication in the public portal. please follow below link for the End User Agreement:

www.umlib.nl/taverne-license

Take down policy

If you believe that this document breaches copyright please contact us at:

repository@maastrichtuniversity.nl

providing details and we will investigate your claim.
}

Copyright and moral rights for the publications made accessible in the public portal are retained by the authors and/or other copyright owners and it is a condition of accessing publications that users recognise and abide by the legal requirements associated with these

- Users may download and print one copy of any publication from the public portal for the purpose of private study or research.

- You may not further distribute the material or use it for any profit-making activity or commercial gain

If the publication is distributed under the terms of Article $25 \mathrm{fa}$ of the Dutch Copyright Act, indicated by the "Taverne" license above, 


\title{
Electrophysiological correlates of automatic spreading of activation in patients with psychotic disorder and first-degree relatives
}

\author{
Stefanie Pfeifer ${ }^{\mathrm{a}, \mathrm{b}}$, Niels O. Schiller ${ }^{\mathrm{c}, \mathrm{d}}$, Jim van Os ${ }^{\mathrm{a}, \mathrm{e}}$, Wim J. Riedel ${ }^{\mathrm{f}}$, Petra Vlamings ${ }^{\mathrm{g}}$, \\ Claudia Simons $^{\text {a, h }}$, Lydia Krabbendam a,i,* \\ a Department of Psychiatry and Neuropsychology, South Limburg Mental Health Research and Teaching Network, EURON, Maastricht University Medical Centre, Maastricht, The Netherlands \\ b BKH Guenzburg, Germany \\ c Leiden University Centre for Linguistics (LUCL), Faculty of Humanities, Leiden University, Leiden, The Netherlands \\ ${ }^{d}$ Cognitive Psychology Unit E' Leiden Institute for Brain and Cognition (LIBC), Faculty of Social Sciences, Leiden University, Leiden, The Netherlands \\ e King's College London, King's Health Partners, Department of Psychosis Studies, Institute of Psychiatry, London SE5 8AF, UK \\ ${ }^{\mathrm{f}}$ Department of Neuropsychology and Psychopharmacology, Faculty of Psychology and Neuroscience, Maastricht University, Maastricht, The Netherlands \\ ${ }^{g}$ Department of Neurocognitive Developmental Psychology, Faculty of Psychology and Neuroscience, Maastricht University, Maastricht, The Netherlands \\ h GGZ Eindhoven, Eindhoven, The Netherlands \\ ${ }^{i}$ Department of Education and Neuroscience, VU University, Amsterdam, The Netherlands
}

\section{A R T I C L E I N F O}

\section{Article history:}

Received 7 June 2011

Received in revised form 6 January 2012

Accepted 13 January 2012

Available online 30 January 2012

\section{Keywords:}

Psychotic disorder

Semantic

Priming

N400

High risk

Event-related potentials

SOA

\begin{abstract}
A B S T R A C T
Background: Semantic network abnormalities in patients with psychotic disorder were examined using associative prime-target relations with two stimulus asynchronies (SOAs; $-250 \mathrm{~ms}$ and $-500 \mathrm{~ms}$ ) to assess the time course of automatic and more controlled processes of semantic priming. To investigate whether an aberrant semantic network system is part of the familial liability for psychosis, healthy siblings of patients with psychotic disorder were additionally examined. The N400 event-related brain potential (ERP) was used as a probe of semantic processing. Method: Twenty-two patients with psychotic disorder, twenty siblings of patients with psychotic disorder and twenty controls participated in a lexical decision task and ERPs were recorded to target words that were associatively, indirectly or not related to their preceding prime word.

Results: Associative priming of the N400 amplitude was found across all participants and both SOAs, but no between-group differences were found for the N400 amplitude (both SOAs). The Group $\times$ Condition interaction of the indirect priming $\mathrm{N} 400$ latency of the three groups was just short of statistical significance (F2,59=2.7, $\mathrm{p}=.077$ ). Patients showed an increased indirect priming effect of the N400 latency only at short SOA, with decreased latency of the indirectly related compared to the unrelated condition, while controls did not show an indirect priming $\mathrm{N} 400$ latency effect. No between-group differences in N400 latency of indirect priming were found at the long SOA. Only a trend towards a Group $\times$ Condition interaction of the indirect priming N400 latency between the sibling and the controls was found, but without a main effect of indirect priming in the sibling group. Conclusion: These preliminary results support the assumption of a hyperactive semantic network in patients with psychotic disorder, which develops under automatic processes and decreases with more controlled processes, but does not represent clear trait familial liability.
\end{abstract}

(c) 2012 Elsevier B.V. All rights reserved.
Abbreviations: RT, reaction time; SOA, stimulus onset asynchrony; ERPs, eventrelated potentials; FTD, formal thought disorder; CASH, Comprehensive Assessment of Symptoms and History; CIDI, Composite International Diagnostic Interview; WAIS, Wechsler Adult Intelligence Scale; GIT, Groninger Intelligence Test; BPRS, Brief Psychiatric Rating Scale; SD, standard deviation; ANOVA, analyses of variance; NOS, not otherwise specified; CPE, chlorpromazine equivalent.

* Corresponding author at: Department of Education and Neuroscience, VU University Amsterdam, Van der Boechorststraat 1, 1081 BT Amsterdam, The Netherlands. Tel.: + 31 20598 8859/598 3606; fax: + 31205988745.

E-mail addresses: s.pfeifer@maastrichtuniversity.nl (S. Pfeifer), N.O.Schiller@hum.leidenuniv.nl (N.O. Schiller), j.vanos@maastrichtuniversity.nl (J.van Os), w.riedel@maastrichtuniversity.nl (W.J. Riedel),

p.vlamings@maastrichtuniversity.nl (P. Vlamings), c.simons@maastrichtuniversity.nl (C. Simons), lydia.krabbendam@vu.nl (L. Krabbendam).

\section{Introduction}

Disturbances of thought and language have long been identified as core features of psychotic disorder (Bleuler, 1950), particularly disorganized thinking, or intrusion of inadequate semantic associational processes (Docherty et al., 1996). Recent theories have posited that disorganized speech in patients with psychotic disorder result from an abnormal increase of spreading of activation in the semantic memory network (Spitzer, 1997).

Support for this hypothesis comes from behavioral reaction time (RT) studies using semantic priming paradigms (Kumar and Debruille, 2004; Moritz et al., 2001b; Spitzer, 1997). Semantic priming refers to the tendency to respond to a target stimulus more 
quickly if the target is preceded by a semantically related prime compared to an unrelated prime. It has been suggested that related words benefit from facilitation processes in the semantic network through an automatic spread of activation from the activated prime (Collins and Loftus, 1975). According to this model, unusual associations appear as disorganization symptoms in speech production, because the activation of associations in the network is increased as a consequence of a disinhibited semantic network. Abnormally large semantic priming effects (enlarged RT difference between the related condition and the unrelated condition) for directly associated words (e.g. glasses - eye) has been found in patients with psychotic disorder and especially in patients with formal thought disorder (FTD) (Chenery et al., 2004; Moritz et al., 2001a; Nestor et al., 2006; Spitzer et al., 1993, 1994). This activation was found to be additionally increased when indirect associates were used (i.e., prime-target relations which are mediated by one other concept e.g. lion - stripes, mediated by the concept "tiger"), indicative of excessive and further spreading of activation in patients with psychotic disorder (Moritz et al., 2001b, 2002).

However, not all studies found increased direct and indirect semantic priming effects in patients with psychotic disorder, but instead described normal (Barch et al., 1996; Vinogradov et al., 1992) or reduced (Ober et al., 1997) effects. Multiple factors may contribute to the emergence - or lack of the semantic priming effect, including short stimulus onset asynchrony ( $\mathrm{SOA}$; the interval between prime and target onset) and semantic relationship (Alario et al., 2000; Moritz et al., 2001b; Nestor et al., 2006). Duration of SOA influences whether automatic or strategic processes operate in the semantic priming effect. When the prime is presented less than about $500 \mathrm{~ms}$ before the target, the mechanism for priming is assumed to be primarily due to automatic activation of the semantic network. At longer SOA, the automatic processes are complemented by controlled processes, meaning that strategic processes and working memory can influence the outcome (Mathalon et al., 2010). It has been suggested that so-called hyperpriming effects, i.e. increased priming, in patients with psychotic disorder may develop mainly under automatic processing, whereas the opposite effect - reduced priming - may result from controlled processes leading to deficient activation of semantically related items (Kreher et al., 2008; Minzenberg et al., 2002; Moritz et al., 2001b). Another source of variance in the semantic priming effect is the relationship between word-pairs. It has been hypothesized that associative relations (e.g. nest - bird) are represented differently in the mental lexicon than categorical relations (e.g. boat - train) (Alario et al., 2000; Cutting and Ferreira, 1999). One study investigated the effect of associative and categorical relationships in patients with psychotic disorder showing that patients had greater priming effects for associated words than for categorically related words (Nestor et al., 2006).

Since RT as the final outcome variable is potentially confounded by all processes that occur between the presentation of the stimulus and the behavioral response, scalp-recorded ERPs provide a more direct measure of neurophysiological events associated with the semantic dysfunction. One ERP component relevant to language processing is the $\mathrm{N} 400$, a negative deflection approximately around $400 \mathrm{~ms}$ after onset of a target word which develops in response to any meaningful stimulus (such as a word). The N400 is sensitive to the expectancy of a word in a given context, with unexpected words producing a larger N400 component than expected words (Kutas and Hillyard, 1980). N400 amplitude can be used to index the degree to which concepts are activated in the semantic network, as a decreased amplitude is indicative of greater activation of these concepts (Kiang et al., 2008). In a typical lexical decision task, the $\mathrm{N} 400$ amplitude increases (i.e., becomes more negative) with semantic distance (more negative in the unrelated condition compared to the related condition) (Weisbrod et al., 1999). This N400 effect was also found with indirect associations under automatic timing processes, albeit to a lesser degree compared to associative relations, suggesting that the N400 is sensitive to automatic spreading of activation processes (Kreher et al., 2006; Weisbrod et al., 1999).

Several ERP studies have investigated the latency of the N400 component. In healthy subjects, the N400 latency was found to resemble behavioral results, with the latest N400 latency for the unrelated condition, the shortest N400 latency for the related condition and the indirectly related condition in between (Kiefer et al., 1998; Weisbrod et al., 1999). A robust finding of previous N400 studies in patients with psychotic disorder was an overall increased latency of the N400 component, suggesting abnormal semantic processing (Nestor et al., 1997) and general slowing of information processing (Kimble et al., 2000; Kumar and Debruille, 2004; Nestor et al., 1997). Spitzer (1997) also reported a decreased N400 latency for the indirectly related condition compared to the unrelated condition, thus showing indirect priming of the N400 latency in patients with psychotic disorder, while this effect was not seen in the healthy control group (Spitzer et al., 1997).

Results of N400 amplitude are more mixed. Increased N400 semantic priming effects have been reported in patients with psychotic disorder, with abnormally small N400 amplitudes to directly associated words (compared to the unrelated condition) in patients with non-FTD (Mathalon et al., 2002, 2010), and indirectly related words in patients with FTD (Kreher et al., 2010, 2008) at short SOA, indicative of a broader spreading of activation in the semantic network. In contrast, abnormally reduced N400 semantic priming effects have also been found in patients with psychotic disorder, with larger N400 amplitudes for the direct and indirect associative conditions (indicating no difference between the associatively/indirectly related and the unrelated N400 amplitude) at short and long SOA (Condray et al., 2003; Kiang et al., 2008). The reasons for the discrepancies in previous studies are not fully understood yet. Recently, in one study of Kreher et al. (2010) it was demonstrated that strategic effects of semantic processes reduces priming, even when automatic experimental conditions (SOA $350 \mathrm{~ms}$ ) were used, and therefore the use of the experimental task would be in part an explanation for the inconsistent results. Therefore, similar to the behavioral studies, methodological differences such as SOA, relationship between word pairs, sample characteristics between the studies or experimental task may play a role (Minzenberg et al., 2002).

One way to further elucidate the nature of the semantic priming effect in patients with psychotic disorder is the study of non-clinical populations with a higher than average risk for developing the disorder, for example, first-degree relatives of patients with psychotic disorder. The advantage of this approach is that some of the confounding variables that may bias patient research can be avoided, e.g. reduced attention capacity, medication and chronic illness (Kimble et al., 2000; Morgan et al., 2006; Moritz et al., 1999). In at-risk populations, similar but less severe impairments have been found in several areas of language function, including semantic priming (Moritz et al., 1999) and word-pronunciation tasks (Kerns and Berenbaum, 2000), and these abnormalities may also be present at the level of the N400 component (Guerra et al., 2009; Niznikiewicz et al., 2004, 1999). The aim of the current study was to extend these findings using a lexical decision paradigm with direct and indirect semantic associations in patients with psychotic disorder, first-degree relatives (siblings) and healthy controls. Such a comparison may also shed light on whether the aberrant semantic network system in psychosis forms part of the familial liability to psychotic disorder.

The aim of the study was to further elucidate the nature of the semantic network system in relation to (liability for) psychotic disorder, by investigating the $\mathrm{N} 400$ component in a semantic priming paradigm in patients and their non-psychotic first-degree relatives. The design of the study allowed controlling for the impact of the type of the semantic association between prime and target (by using associative prime-target relations only) and SOA (by tapping 
automatic ( $\mathrm{SOA}-250 \mathrm{~ms}$ ) to more controlled (SOA $-500 \mathrm{~ms}$ ) processes and investigating a possible latency shift of the semantic priming effect with this increase of SOA).We expected that across all participants, the N400 would be largest (most negative) and latest to the unrelated condition, but smallest (most positive) and earliest to the associative condition. The N400 of the indirect condition was expected to be smaller and earlier compared to the unrelated condition, a pattern consistent with previous findings (Weisbrod et al., 1999). If psychotic disorder is associated with a hyperactive semantic network, the results should show increased associative N400 priming effects. Since indirectly related word pairs were an additional and stronger indicator of excessive spreading of activation in the semantic network, it was hypothesized that prime words would activate indirectly related targets even more strongly in patients than in the control group. This effect will be strongest at SOA $-250 \mathrm{~ms}$, assuming that an increase in SOA would lead to an increase of controlled processes. If an aberrant semantic network system forms part of the familial liability to psychosis, the results for siblings should resemble those of the patients, although at smaller effect size.

\section{Methods}

\subsection{Participants}

The study sample consisted of patients with a diagnosis of nonaffective psychosis, first-degree relatives (siblings) of patients with non-affective psychosis and controls from the general population. Inclusion criteria of the participants of the present study were the following: (i) patients with a history of a non-affective psychosis according to the DSM-IV and first contact with mental health facilities within the last ten years; (ii) siblings of these patients, free of any lifetime non-affective psychotic disorder; (iii) healthy control participants without the occurrence of any psychotic disorder in either the participant him/herself or any first-degree relatives. Initial selection criteria for all participants were: between 18 and 50 years of age; native speakers of the Dutch language; an IQ value above 80 ; normal or corrected to normal vision, no history of dyslexia or neurological disorders such as epilepsy and or concussion with loss of consciousness, no psychotic disorder due to a general medical condition and no alcohol and drug related substance disorder according to the DSM-IV.

Patients were recruited from mental health services and psychiatric hospitals through caseloads of selected representative clinicians. All siblings were sampled through participating patients. Control participants were recruited through random mailings in nearby municipalities and through advertisements in newspapers. The Comprehensive Assessment of Symptoms and History (CASH (Andreasen et al., 1992)) sections on affective and psychotic disorders were used to confirm the presence of a diagnosis of non-affective psychosis in patients, the absence of such a diagnosis in siblings, and absence of a lifetime diagnosis of any psychotic disorder or any current affective disorder in the healthy controls. Additionally, current drug use was assessed with the Composite International Diagnostic Interview (CIDI; (Smeets and Dingemans, 1993) and IQ was assessed with the short version of the WAIS III (Wechsler, 1997). Participants also completed the wordlist subtest of the Groninger Intelligence Test (GIT) as an estimate of general cognitive ability (Luteijn and van der Ploeg, 1983).

The standing ethics committee of Maastricht University Medical Centre approved the study. All participants signed an informed consent conforming to the local ethics committee guidelines. Participants received financial compensation for time and travel associated with the study.

\subsection{Assessment of symptomatology}

The Brief Psychiatric Rating Scale (BPRS) version 24 (Lukoff et al., 1986) was used to determine the severity of positive, negative, depressive and disorganized symptomatology over the last two weeks. The BPRS is a semi-structured interview that consists of 24 items measuring positive/psychotic, negative, disorganized and depressive symptoms. The severity of symptoms of each item was assessed using a seven-point Likert rating scale (with 1 indicating "absent" and 7 indicating "very severe"). Weighted averages and subsequently standardized scores were calculated for each participant. Further, the formal thought disorder scale of the CASH interview, including nine observation items, was used to assess the state of current disorganized thinking. The severity of symptoms of each item was assessed using a five-point Likert rating scale (with 0 indicating "absent" and 4 indicating "very severe"). Weighted averages and subsequently standardized scores were calculated for each participant.

\subsection{Design and materials}

The lexical decision task consisted of a prime word followed by a target word in four different experimental conditions: associative, indirect, unrelated and nonword condition. All stimuli consisted of 258 pairs of letter strings (primes and targets). All primes were real Dutch words. Half of the targets were existing Dutch words, and half of the targets were nonwords conforming to Dutch phonotactics. The 129 prime-target combinations with existing target words consisted of 43 associative pairs, 43 indirectly related pairs, and 43 unrelated pairs. Additionally, another 129 nonword combinations were presented. The experiment consisted of two separate blocks of $-250 \mathrm{~ms}$ and $-500 \mathrm{~ms}$ (the prime was presented 250 or $500 \mathrm{~ms}$ before the target) SOA (hereafter short and long SOA). The prime-target pairs differed across the experimental conditions, but were the same for both SOAs.

The participants received ten additional practice trials to familiarize them with the experimental procedure. These trials were taken from the same source as the other trials (described below) and were not used in the experiment. The practice trials were presented in the same order for each participant.

All prime-target pairs for each SOA were presented in four blocks, two consisting of 64 trials and two of 65 trials. Therefore, each participant received eight blocks in total. The trials in the eight blocks were presented in random order. The four blocks in each separate SOA were counterbalanced. Finally, the short and the long SOA were counterbalanced across the participants. Additionally, the first two trials of each block were added as warm-up trials (taken from the same source as the other trials and not used in the experiment). After each block, a short period of rest was provided.

All words were chosen from different semantic categories (e.g. animals, vehicles, body parts, food). Pairs of associative, indirectly related and unrelated words were selected according to the following criteria: Associative word pairs were based on a meaning relation (e.g. glasses - EYE) and were not from the same semantic category (e.g. body parts). Indirectly related word pairs were based on a meaning relation between the prime and the mediator and between the mediator and the target (e.g. white - MOUNTAIN, mediated by "snow"), without being from the same semantic category. Further, prime and target of indirectly related word pairs were not associatively related. Unrelated word pairs had neither an associative nor an indirect relation (e.g. car - TABLE).

Most word pairs of the associative and the indirect condition were derived from several Dutch association norms (de Groot and de Bil, 1987; Lauteslager et al., 1986; Starreveld and La Heij, 1996). The associations of the remaining associative and indirect word pairs were gathered in our laboratory, where 23 healthy subjects, other than those participating in the present study, were given a sheet with words and were instructed to write down the word association first coming into their mind for each word. Word pairs of the unrelated condition were derived according to the selection criteria that no association and indirect association were found between prime and target. Phonotactically legal nonwords were pronounceable letter strings (e.g. 
PONT) that were selected from two nonword databases (Zeelenberg and Pecher, 2002), based on existing Dutch words with change of at least one letter. The nonwords were matched with the words of the other conditions for word length and identity of first letter.

The prime words of each experimental condition had a mean frequency of occurrence of 63.6 per million $(S D=131.5$, range: $0.3-820)$ for the associative condition; 36.4 per million $(S D=45.6$ range: $2-190)$ for the indirect condition and 36.0 per million $(S D=46.93$ range: $0.2-178$ ) for the unrelated condition, as determined by the CELEX data base (Baayen et al., 1995). Prime words across conditions were comparable regarding word frequency $(\mathrm{F}=1.4 ; \mathrm{p}>0.05)$. The target words of each experimental condition had a mean frequency of occurrence of 191.6 per million ( $S D=729.6$, range: $0.1-4534$ ) for the associative condition; 109.4 per million ( $S D=166.2$, range: 1-961) for the indirect condition and 126.0 per million $(S D=263.4$, range: $0.5-1219$ ) for the unrelated condition, as determined by the CELEX data base (Baayen et al., 1995). Target words across conditions were comparable regarding word frequency $(\mathrm{F}=0.5 ; \mathrm{p}>0.05)$.

Furthermore, phonological overlap and rhymes were controlled for each prime-target pair. Word length (word length was between 3 and 10 characters) and number of syllables were matched and did not differ between the experimental conditions ( $p>0.05$ ). Additionally, word length of the experimental conditions was matched with word length of the nonword condition.

\subsection{Task procedure}

All participants were tested individually in an electrically shielded, soundproof chamber at Maastricht University. The participants were seated in front of a computer screen on which the stimuli were presented. During the experiment, both prime and target words were presented in white against a black background, at the same position as the fixation cross, in the middle of the screen with a viewing distance of approximately $72 \mathrm{~cm}$. The words were presented in lower case letters (font size: 30 points, style: Courier new).

Participants were instructed to rest their arms and hands on the table and were informed not to speak, blink or move their eyes while the words are presented on the screen. Online EEG data recordings were collected with Neuroscan software (Neuroscan version 4.2). In the experiment, participants were presented with the prime word, followed by the target word. The task of the participants was to press a button as quickly and accurately as possible to indicate whether the target is an existing word or a nonword. The participants were instructed to press a right button for a word and a left button for a nonword.

Every trial consisted of the following sequence of stimuli. First, a fixation cross was presented for $500 \mathrm{~ms}$. Second, a blank screen was presented for $200 \mathrm{~ms}$ in order to minimize after effects of the fixation cross. Third, the prime word was presented for $250 \mathrm{~ms}$. Fourth, with the appropriate SOA, the target stimulus was presented until the participant gave a response, but for maximum of $2000 \mathrm{~ms}$. After the disappearance of the target stimulus and the next fixation cross, a blank screen was presented for $1500 \mathrm{~ms}$. The experiment was programmed with the software Presentation (NeurobehaviouralSystems, 2006) which also registered RTs of button presses responses, measured from the onset of the target stimulus.

\subsection{EEG recording procedure and data-analysis}

Participants were asked to sleep normally the night before the experiment and to avoid drugs and alcohol the day before the experiment. Electrophysiological data were continuously collected from the scalp via a 64-channel system, using an EasyCap according to the international $10 \%$ system (equidistant electrodes). The on-line reference electrode was placed at the left mastoid and it was rereferenced off-line to the mean of the activity at the two mastoids. The FC5 electrode was used as ground electrode. Signals were filtered with a $.05-100 \mathrm{~Hz}$ band pass filter and digitized at $500 \mathrm{~Hz}$. A bipolar montage placed on the left upper and lower orbital ridge monitored eye blinks and vertical eye movements. Lateral eye movements were measured with a bipolar montage placed on the right and left external cantus. Electrode impedance for each electrode was kept below $5 \mathrm{k} \Omega$.

During off-line processing of the continuously collected EEG data, epochs of $1350 \mathrm{~ms}$ were obtained, including a $450 \mathrm{~ms}$ pre-stimulus interval for the short SOA experiment and epochs of $1600 \mathrm{~ms}$, including a $700 \mathrm{~ms}$ pre-stimulus interval for the long SOA experiment. Those trials contaminated by eye movements or amplifier blocking were removed (Gratton et al., 1983). Baseline correction was done with two different intervals (using an interval from -450 to $250 \mathrm{~ms}$ before target onset for the short SOA and from -700 to $-500 \mathrm{~ms}$ before target onset for the long SOA), to avoid an influence of the prime word into the analyzed intervals of the target. After baseline correction, the signal was filtered with a $1-30 \mathrm{~Hz}$ band pass filter (12 dB/oct). Any activation of the scalp or eye monitoring below $-75 \mu \mathrm{V}$ and above $+75 \mu \mathrm{V}$ was considered an artifact and was rejected from further analysis. Furthermore, all trials with incorrect responses were rejected from the dataset. Finally, ERPs were computed for each electrode by averaging the remaining trials for each stimulus condition. ERPs were averaged across groups.

For each condition, N400 latency was defined as the interval between target onset and the largest negative peak from 270 to $520 \mathrm{~ms}$ post-target onset for both SOA experiments for the control and the sibling group and $240-540 \mathrm{~ms}$ for the patient group. All peaks at the $\mathrm{CZ}$ electrode were confirmed by visual inspection and corrected manually. This adjustment remained in the interval of 270-520 ms for both SOAs. N400 amplitude was defined as the mean voltage from 270 to $520 \mathrm{~ms}$ post-stimulus for both SOA experiments for the control and the sibling group and $240-540 \mathrm{~ms}$ for the patient group.

\subsection{Statistical analysis}

All analyses were carried out using SPSS version 16 (SPSS, 2008). First, RTs and errors were analyzed to evaluate the validity of the paradigm. Analyses of variance (ANOVAs) were conducted to test main effects of condition, group and their interactions at both SOAs separately. This resulted in $3 \times 2$ ANOVA with 3 levels of the betweensubject factor Group (controls, siblings, patients) and 2 levels of the within-subject factor Condition (associatively related vs. unrelated; indirectly related vs. unrelated), separate for the RTs and errors.

Second, for the ERP analysis, a series of planned mixed model repeated measure analyses of variance (ANOVAs) was performed for 21 electrodes (FZ, CZ, PZ, F3, F5, C3, C5, P3, P5, P03, T7, CP5, F4, F6, C4, C6, P4, P6, P04, T8, CP6). A priori, we were interested in differences between the three groups in the associative N400 priming effect (associative vs. unrelated) and the indirect N400 priming effect (indirect vs. unrelated) for both SOAs separately (short and long). Therefore, separately for each SOA, N400 mean amplitude and peak latency, analyses were conducted by a 3 (Group: controls, siblings, patients) $\times 2$ (Condition: associative vs. unrelated; indirect vs. unrelated) $\times 21$ (21 Electrodes) ANOVA. Any significant Group $\times$ Condition interaction was followed by a separate group comparison in order to specifically investigate differences in associative and indirect N400 between two groups. In order to do so, a 2 (Group: controls vs. patients; controls vs. siblings) $\times 2$ (Condition: associative vs. unrelated; indirect vs. unrelated) ANOVA was conducted. Any significant interaction between Group and Condition was followed by within-group ANOVAs to establish whether the N400 priming effects were significant within each group independently (Kreher et al., 2008). Finally, to investigate scalp distribution, any significant Condition $\times$ Electrode effect was further investigated with a 2 (Condition: associative vs. unrelated; indirect vs. unrelated) $\times 3$ (Electrode: 
central (FZ, CZ, PZ), left (F3, F5, C3, C5, P3, P5, P03, T7, CP5) and right (F4, F6, C4, C6, P4, P6, P04, T8, CP6)) ANOVA.

All ANOVAs underwent Greenhouse-Geisser epsilon correction to protect against type 1 error resulting from violations of sphericity (Greenhouse and Geisser, 1959). Since we tested a priori specified hypotheses, the significance level alpha was set at .05.

In an exploratory analysis in patients with psychotic disorder, the relationship between associative priming/indirect priming and the symptom of formal thought disorder was investigated by calculating Pearson's correlation coefficients. Difference scores were calculated for the associative priming and the indirect priming effect, by subtracting the unrelated condition - the associative condition (Associative Priming) and by subtracting the unrelated condition - the indirect condition (Indirect Priming) at the N400 peak latency/mean amplitude at CZ (where N400 effects were maximal), separate for both SOAs. The formal thought disorder scale of the CASH interview was used to assess the state of current disorganized thinking.

\section{Results}

\subsection{Sample}

The sample initially consisted of 25 patients with a non-affective psychosis, 24 siblings of patients and 22 healthy controls. Due to technical difficulties, three participants of the patient group, four of the sibling group and two of the control group were excluded.

The final study group thus consisted of 22 patients, 20 siblings and 20 controls pertaining to 55 different families. All three groups were frequency-matched on age, gender and education. Patients had lower IQ compared to the siblings $(\mathrm{F} 1,40=4.7 ; \mathrm{p}<.05)$ but not compared to the controls ( $p>0.1$ ), and controls and siblings did not differ on IQ either ( $p>0.1)$. The three groups did not differ on either vocabulary as assessed with the Groningen Intelligence Test (GIT) or drug use in the last year. Patients had higher levels of psychopathology. In the control group, all subjects were right-handed. In the sibling group, one subject was left-handed and in the patient group two subjects were left-handed. Socio-demographic and psychopathological characteristics of the sample are given in Table 1.
Eleven patients met the criteria for schizophrenia/paranoid type, two for schizophrenia/undifferentiated type, two for schizoaffective disorder, two for psychotic disorder NOS and two for schizophreniform disorder; one patient met the criteria for schizophrenia/residual type, one for schizophrenia/residual chronic type and one for schizophrenia/disorganized type. Five siblings met the criteria for Major Depressive Disorder, Single Episode, in full remission and two met the criteria for Major Depressive Disorder, recurrent, in partial remission.

At the time of testing, fifteen patients received second-generation antipsychotics (i.e. six patients risperidone, three aripiprazole, two amisulpride, two olanzapine, one quetiapine, and one clozapine) and two patients were taking first generation antipsychotics (i.e. one haloperidol and one pimozide). One patient received two different types of second-generation antipsychotics (olanzapine, aripripazole), one patient received a combination of one first and one second-generation antipsychotic (haloperidol and aripripazole) and one patient received one first-generation and two secondgeneration antipsychotics (clothiapine, risperidone and amisulpride). Two patients were not currently taking any medication. The mean chlorpromazine equivalent ( $\mathrm{CPE}$ ) is given in Table 1. All siblings were medication-free at the time of testing.

\subsection{Behavioral data}

In order to normalize the data, RTs of more than three standard deviations from the mean of each participant were considered as outliers and were excluded from the RT analyses (La Heij et al., 1990). All trials in which participants gave incorrect responses were excluded from the RT analyses. The mean number of trials that were used in the short SOA experiment for the associative, indirect and unrelated condition was: 42.0 (SD: 0.8), 41.0 (SD: 1.6) and 41.5 (SD: 1.4), respectively for the patients; 42.3 (SD: 0.9 ), 41.3 (SD: 1.2 ) and 41.6 (SD: 1.1), respectively for the siblings; and 42.5 (SD: 0.7 ), 41.3 (SD: 1.7 ) and 41.5 (SD: 1.4 ), respectively for the controls. In the long SOA experiment, the mean number of trials for the associative, indirect and unrelated condition was: 41.9 (SD: 1.3), 41.1 (SD: 1.3) and 41.7 (SD: 1.0), respectively for the patients; 42.4 (SD: 0.7), 41.5

Table 1

Demographic and clinical characteristics of the groups.

\begin{tabular}{|c|c|c|c|c|c|}
\hline & \multirow{2}{*}{$\frac{\text { Controls }(\mathrm{N}=20)}{\text { Mean }(\mathrm{SD})}$} & \multirow{2}{*}{$\frac{\text { Siblings }(\mathrm{N}=20)}{\text { Mean }(\mathrm{SD})}$} & \multirow{2}{*}{$\frac{\text { Patients }(\mathrm{N}=22)}{\text { Mean }(\mathrm{SD})}$} & \multirow{2}{*}{$\begin{array}{l}\text { Group } \\
\text { comparisons }^{\mathrm{a}}\end{array}$} & \multirow{2}{*}{$\begin{array}{l}\text { Pairwise } \\
\text { comparisons }^{\mathrm{b}, \mathrm{c}}\end{array}$} \\
\hline & & & & & \\
\hline Age (years) & $32.1(10.7)$ & $32.2(8.1)$ & $29.7(8.3)$ & $\mathrm{F} 2,59=0.5 ; \mathrm{p}>.10$ & \\
\hline Education (level achieved) & $5.9(1.6)$ & $6.2(1.3)$ & $5.6(1.9)$ & $\mathrm{F} 2,59=0.8 ; \mathrm{p}>.10$ & \\
\hline Gender $(\mathrm{m} / \mathrm{f})$ & $9 / 11$ & $12 / 08$ & $12 / 10$ & $\mathrm{Chi}^{2, \mathrm{~d}}=0.9 ; \mathrm{p}>.10$ & \\
\hline IQ & $108.0(11.2)$ & $109.8(17.6)$ & $99.5(13.4)$ & $\mathrm{F} 2,59=3.2 ; \mathrm{p}<.05$ & $\mathrm{P}<\mathrm{S}$ \\
\hline GIT (words) & $14.4(1.07)$ & $14(2.0)$ & $13.8(2.2)$ & $\mathrm{F} 2,59=0.5 ; \mathrm{p}>.10$ & \\
\hline Drug use \% & $5.0 \%$ & $15 \%$ & $4.6 \%$ & $\mathrm{~F} 2,59=0.9 ; \mathrm{p}>.10$ & \\
\hline Medication (CPE mg) & - & - & $521(545)$ & & \\
\hline Length of illness (years) & - & - & $6.28(2.4)$ & Range: $2.9-10$ & \\
\hline \multicolumn{6}{|l|}{ Psychotic symptom scores } \\
\hline \multicolumn{6}{|l|}{ BPRS } \\
\hline Positive & $1.02(0.06)$ & $1.13(0.21)$ & $1.76(1.03)$ & $\mathrm{F} 2,59=8.6 ; \mathrm{p}<.00$ & $\mathrm{P}>\mathrm{S}, \mathrm{C}$ \\
\hline Negative & $1.13(0.16)$ & $1.34(0.68)$ & $1.71(0.48)$ & $\mathrm{F} 2,59=7.6 ; \mathrm{p}<.00$ & $\mathrm{P}>\mathrm{S}, \mathrm{C}$ \\
\hline Depressive & $1.34(0.54)$ & $1.58(0.72)$ & $2.21(1.16)$ & $\mathrm{F} 2,59=5.9 ; \mathrm{p}<.01$ & $P>S, C$ \\
\hline Disorganized & $1.08(0.11)$ & $1.15(0.25)$ & $1.29(0.28)$ & $\mathrm{F} 2,59=4.7 ; \mathrm{p}<.05$ & $\mathrm{P}>\mathrm{C}$ \\
\hline Total & $1.13(0.15)$ & $1.27(0.30)$ & $1.66(0.50)$ & $\mathrm{F} 2,59=11.2 ; \mathrm{p}<.00$ & $P>S, C$ \\
\hline \multicolumn{6}{|c|}{ CASH formal thought disorder score } \\
\hline FTD & - & - & $0.126(0.25)$ & & \\
\hline
\end{tabular}

Notes: GIT, Groninger Intelligence Test; BPRS, Brief Psychiatric Rating Scale; CASH, Comprehensive Assessment of Symptoms and History.

a Group differences were tested by one-way analysis of variance (ANOVA).

b Pairwise group differences were tested with Bonferroni pairwise comparisons.

c Significant differences between groups at the $\mathrm{p}<.05$ level were listed: $\mathrm{C}=$ Controls, $\mathrm{S}=\mathrm{Sibs}, \mathrm{P}=$ Patients.

d Gender differences between groups were tested by Chi-square analysis. 
(SD: 1.1) and 41.6 (SD: 1.1), respectively for the siblings; and 42.5 (SD: 0.8 ), 41.3 (SD: 1.8 ) and 41.3 (SD: 1.6), respectively for the controls. For both SOAs, there was no significant difference between the three groups with respect to the number of trials of each condition.

Mean RTs and error rates of each group, condition and each SOA are given in Table 2 .

\subsubsection{Reaction time analysis}

There was a main effect of Condition at short SOA (F1,58 $=28.12$, $\mathrm{p}<.001)$ and long SOA $(\mathrm{F} 1,58=16.51, \mathrm{p}<.001)$, with decreased RTs for the associative compared to the unrelated condition (associative priming) across all participants. All other main effects of Condition and Group and Condition $\times$ Group interaction were not significant $(\mathrm{p}>0.5)$.

\subsubsection{Error analysis}

Overall, the rates of correct responses of the three groups showed that participants were attending to the stimuli. There was a main effect of Condition at short SOA $(\mathrm{F} 1,58=16.34, \mathrm{p}<.001)$ and long SOA ( $F 1,58=15.53, \mathrm{p}<.001)$, with higher accuracy for the associated condition than for the unrelated condition across all participants. All other main effects of Condition and Group and Condition $\times$ Group interaction were not significant $(p>0.5)$.

\subsection{Event-related potential analysis}

Grand average ERPs of the associative N400 priming effect and the indirect N400 priming effect are shown in Figs. 1 and 2, respectively, for the control, the sibling and the patient group.

\subsubsection{N400 amplitude: associative and indirect N400 priming}

There was no significant main effect of Group across all conditions (associative vs. unrelated; indirect vs. unrelated) and SOAs (all Fs $2,59<2.0$, all ps $>.1$ ). Reflected by significant main effects of Condition (associative vs. unrelated) at short SOA (F 1,59=21.3, p<.001) and long SOA $(\mathrm{F} 1,59=23.5, \mathrm{p}<.001)$, an associative $\mathrm{N} 400$ priming effect across all participants was shown, with more negative amplitudes of the unrelated condition compared to the associative condition. Although the difference in N400 amplitude between the associative and the unrelated condition was broadly distributed over the scalp, the difference was largest central and over the right hemisphere for short SOA (Condition $\times$ Electrode interaction: F20,1180 = 8.7, $\mathrm{p}<.001$ ), and central for long SOA (Condition $\times$ Electrode interaction: $\mathrm{F} 20,1180=4.0, \mathrm{p}=.005$ ). This distribution was consistent with previous studies of word reading (Federmeier and Kutas, 1999; Kiang and Kutas, 2005; Kiang et al., 2008).

The main effects of the indirectly related compared to the unrelated condition were not significant at both SOAs (short SOA: $\mathrm{F} 1,59=0.3, \mathrm{P}>.5$; long SOA: $\mathrm{F} 1,59=2.5, \mathrm{p}>.1$ ). There was no Group $\times$ Condition interaction in the three groups across both conditions (associative vs. unrelated; indirect vs. unrelated) and SOAs (all Fs $2,59<1.2$; all ps $>.3$ ).

\subsubsection{N400 latency}

3.3.2.1. Latency effect: associative $N 400$ priming. There was no significant main effect of Group at short $(F 2,59=0.1, \mathrm{p}>.8)$ and long SOA $(\mathrm{F} 2,59=.9, \mathrm{p}>.3)$. Comparisons between the associatively related and unrelated conditions showed a significantly earlier N400 for the associative condition across all participants and both SOAs, indicated by significant main effects of Condition (short SOA: F1,59=26.1, $\mathrm{p}<.001$; long SOA: F1,59=8.6, $\mathrm{p}=.005$ ). The difference between the associative and the unrelated condition was broadly distributed over the scalp for both SOAs (short SOA: Condition $\times$ Electrode interaction: $\mathrm{F} 20,1180=0.6, \mathrm{p}>.4$ ), however, at long SOA it was largest at the right hemisphere (Condition $\times$ Electrode interaction: F20,1180 $=2.0$, $\mathrm{p}=.040$ ). There was no Group $\times$ Condition interaction of the three groups, indicating that the degree of associative priming of N400 latency was similar across the three groups (short SOA: F1,59=.5, p>.6; long SOA: F1,59=.1, p >.9).

\subsubsection{Latency effect: indirect N400 priming}

3.3.2.2.1. SOA $250 \mathrm{~ms}$. There was no significant main effect of Group $(\mathrm{F} 2,59=0.04, \mathrm{p}>.9)$. The main effect of Condition was marginally significant $(F 1,59=3.0, p=.087)$, showing faster $N 400$ latencies of the indirect condition compared to the unrelated condition (indirect priming) broadly distributed over the scalp (Condition $\times$ Electrode interaction: $F 20,1180=1.0, p>.4$ ). The Group $\times$ Condition interaction of the three groups approached significance $(F 2,59=2.7, \mathrm{p}=.077)$. The $2 \times 2$ ANOVAs showed a significant Group $\times$ Condition interaction in the control and patient group $(\mathrm{F} 1,40=5.0, \mathrm{p}=.030)$ and a marginally significant interaction in the control and sibling group $(F 1,38=3.8$, $\mathrm{p}=.059$ ). The within-group ANOVA in the control group showed no difference in N400 latency between the indirect and the unrelated condition $(\mathrm{F} 1,19=1.1, \mathrm{p}>.3$; mean difference between the unrelated and the indirect condition: $-5.20 \mathrm{~ms}$ ). In contrast, patients did show a significant increase in indirect priming of the $\mathrm{N} 400$ latency $(\mathrm{F} 1,21=4.5$, $\mathrm{p}=.046$ ), with faster $\mathrm{N} 400$ of the indirect compared to the unrelated condition (mean difference: $11.55 \mathrm{~ms}$ ). Siblings did not show a statistical difference between the two conditions $(F 1,19=2.7$, $\mathrm{p}=.116$ ), however, the numerical values showed the same pattern of an indirect priming effect as the patient group (mean difference: $11.15 \mathrm{~ms}$, see Fig. 3). There was no Group $\times$ Condition $\times$ Electrode interaction, indicating that the indirect N400 latency priming effect was broadly distributed over the scalp (controls vs. patients: $\mathrm{F} 20,800=1.0, \mathrm{p}>.4$, controls vs. siblings $\mathrm{F} 20,700=1.0, \mathrm{p}>.4$ ).

3.3.2.2.2. SOA $500 \mathrm{~ms}$. There was no significant main effect of Group (F2,59=0.9, p> .4). Comparisons between the indirectly related and unrelated condition showed a significantly earlier N400 for the indirect condition across all participants, indicated by a significant

Table 2

Mean reaction times were listed for SOA $-250 \mathrm{~ms}$ and SOA $-500 \mathrm{~ms}$, each condition and each group.

\begin{tabular}{|c|c|c|c|c|c|c|}
\hline & \multicolumn{3}{|l|}{ SOA -250} & \multicolumn{3}{|l|}{ SOA -500} \\
\hline & Controls $(\mathrm{N}=20)$ & Siblings $(N=20)$ & Patients $(\mathrm{N}=22)$ & Controls $(N=20)$ & Siblings $(N=20)$ & Patients $(\mathrm{N}=22)$ \\
\hline \multicolumn{7}{|c|}{ Mean reaction time (SD) } \\
\hline Associative & $617.9(101.2)$ & $656.8(100.4)$ & $669.6(174.9)$ & $576.1(94.4)$ & $613.2(80.7)$ & $673.0(188.1)$ \\
\hline Indirect & $643.4(97.5)$ & $678.0(94.6)$ & $694.9(173.5)$ & $601.6(93.3)$ & $625.0(76.0)$ & $696.0(180.6)$ \\
\hline Unrelated & $640.1(108.2)$ & $672.7(94.4)$ & $697.9(181.7)$ & $601.5(95.4)$ & $634.3(82.1)$ & $684.0(180.6)$ \\
\hline \multicolumn{7}{|c|}{ Correct response \% (SD) } \\
\hline Associative & $98.7(1.60)$ & $98.4(2.0)$ & $97.8(2.0)$ & $98.6(1.9)$ & $98.6(1.6)$ & $97.4(3.1)$ \\
\hline Indirect & $96.1(3.85)$ & $96.0(2.8)$ & $95.4(3.7)$ & $95.9(4.1)$ & $96.5(2.7)$ & $95.5(3.1)$ \\
\hline Unrelated & $96.5(3.33)$ & $96.7(2.7)$ & $96.5(3.4)$ & $96.2(3.6)$ & $96.6(2.4)$ & $96.9(2.31)$ \\
\hline
\end{tabular}

Notes: Reaction time in ms. 
Associative Priming SOA - 250
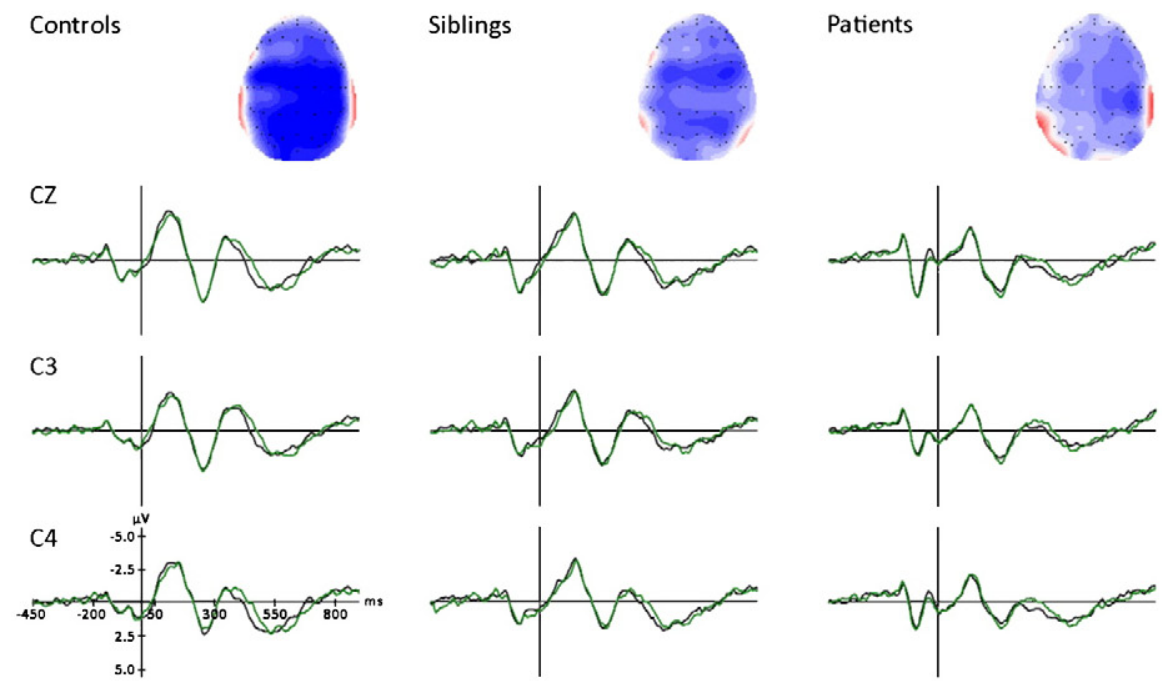

Associative Priming SOA - 500
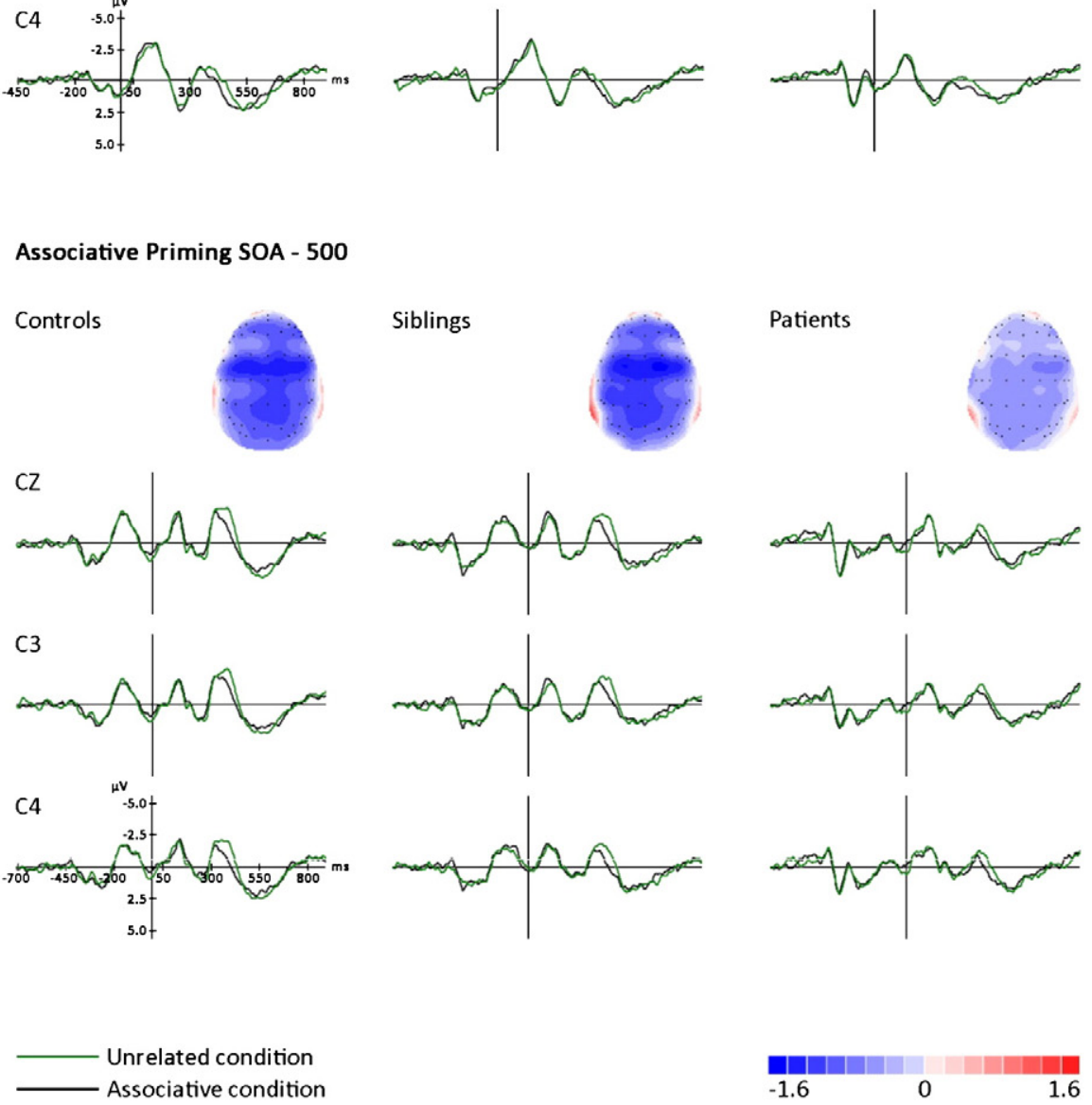

Fig. 1. ERPs to the unrelated and associative condition at three electrode sites. Voltage maps show the scalp distribution of the differences in ERPs of the unrelated - associatively related condition.

main effect of Condition $(\mathrm{F} 1,59=5.7, \mathrm{p}=.020)$ and broadly distributed over the scalp (Condition $\times$ Electrode interaction: $\mathrm{F} 20,1180=0.9$, $\mathrm{p}>.5$ ). There was no Group $\times$ Condition interaction of the three groups $(F 2,59=0.91, p>.9)$, showing that the degree of indirect priming of the N400 latency was similar across the three groups

3.3.3. Exploratory correlational analyses of $N 400$ associative priming/ indirect priming and formal thought disorder in patients with psychotic disorder

Higher formal thought disorder scores were correlated with slower N400 latencies of the indirect condition $(r=0.51 ; p=0.014)$ at long SOA. All other correlations between formal thought disorder scores and the N400 latency and amplitude were not significant (rs between -0.11 and $0.36 ; \mathrm{p}>.1$ in all cases).

\section{Discussion}

This study examined associative and indirect semantic priming effects by investigating the amplitude and the latency of the ERP N400 component in patients with psychotic disorder and in siblings of patients with psychotic disorder, to further elucidate semantic network abnormalities in psychosis. In line with the initial hypothesis, all participants showed an associative priming effect of the N400 amplitude and latency, with the largest (most negative) and latest N400 to the unrelated condition and the smallest (least negative) and earliest N400 to the associative condition. Thus, consistent with earlier studies (Kiang et al., 2008; Kutas and Hillyard, 1980; Weisbrod et al., 1999), our data showed that the N400 is a sensitive index of the structure of the semantic network. Further, the current paradigm elicited priming 
Indirect Priming SOA - 250

Controls

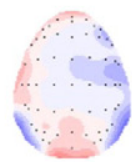

$\mathrm{CZ}$

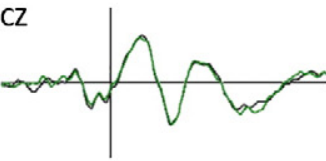

C3

C4

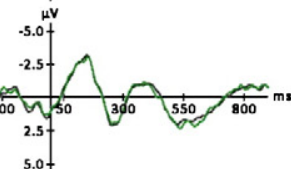

Indirect Priming SOA - $\mathbf{5 0 0}$

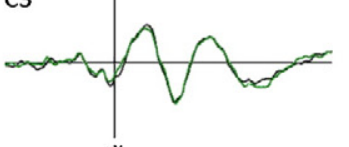

Siblings
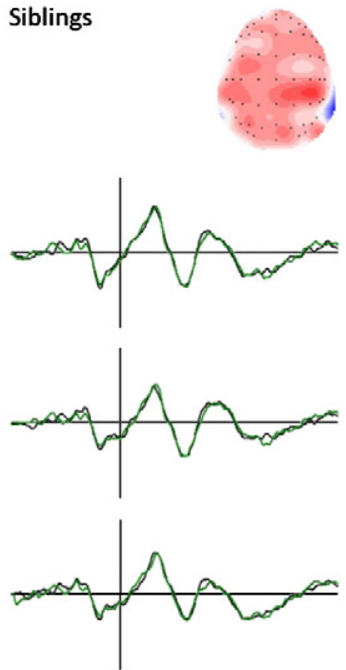

Siblings
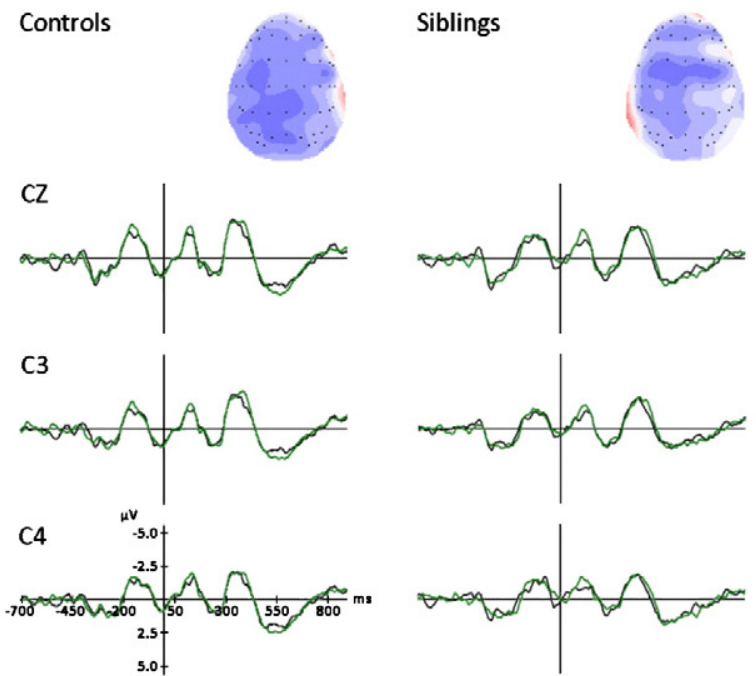

Patients
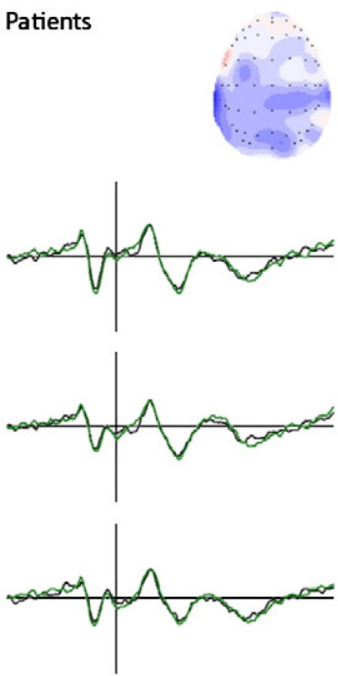

Patients
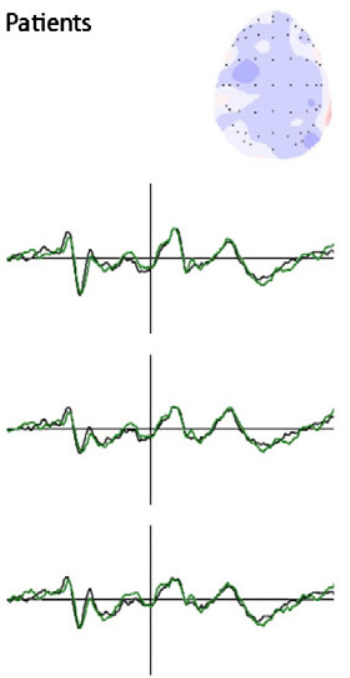

\section{Unrelated condition \\ Indirect condition}

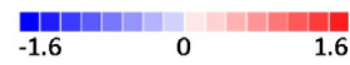

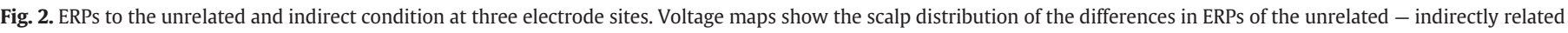
condition.

effects at two different SOAs (short: SOA $-250 \mathrm{~ms}$ and long: SOA $-500 \mathrm{~ms}$ ), making it possible to assess the time course of automatic and more controlled processes of semantic priming.

Under automatic processing at short SOA, patients with psychotic disorder showed indirect priming of the N400 latency, with decreased latency of the indirect compared to the unrelated condition, while controls did not show an indirect priming N400 latency effect. This latency priming effect in patients was found only at short SOA, whereas no between-group differences in N400 latency of indirect priming were found at the long SOA. This supports the assumption of an enhanced spreading activation network in patients with psychotic disorder developing under automatic processes and decreasing with more controlled processes (Mathalon et al., 2002, 2010).
The increased indirect priming effect of the N400 latency in patients with psychotic disorder is largely consistent with earlier behavioral studies under automatic processing, where patients showed faster RTs to the indirect compared to the unrelated condition, whereas controls did not show increased indirect priming effects (Chenery et al., 2004; Manschreck et al., 1988; Moritz et al., 2002; Spitzer et al., 1993; Weisbrod et al., 1998). The results of the RTs of the present study did not show faster RTs to the indirect compared to the unrelated condition, nor an indirect semantic priming differences between groups. This may be due to the relatively small sample size, suggesting that priming effects at behavioral level were primarily observable with larger sample sizes (Spitzer et al., 1993). The dissociation of the behavioral results and the N400 latency possibly indicates an increased sensitivity of neurophysiological markers 


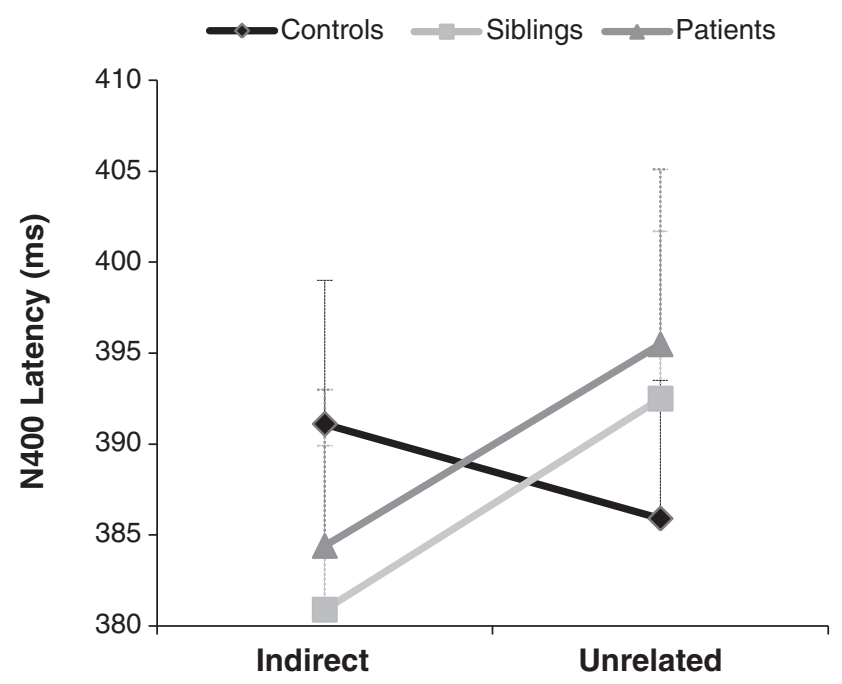

Fig. 3. Indirect N400 latency priming effect. Group mean N400 latencies (+ standard error of the mean) of the indirect and the unrelated condition for the SOA $-250 \mathrm{~ms}$ are shown for the control, sibling and the patient group.

to semantic processing abnormalities in patients with psychotic disorders. This may be the case because at the behavioral level, RT may be influenced by controlled processes, for example, response selection, inhibition and execution. The N400 is a more direct measure of neural processes, providing an earlier time window of the cognitive processes underlying semantic priming than behavioral measures (Spitzer et al., 1997), and therefore being a more sensitive index of automatic semantic processes.

Further, contrary to many earlier studies, which showed an overall increased latency of the N400 component (Kimble et al., 2000; Kumar and Debruille, 2004; Nestor et al., 1997), no significant overall slowing of the $\mathrm{N} 400$ component was found in patients in the present study. This may possible be due to the fact that the patient sample consisted solely of out-patients and therefore likely had a higher level of functioning, and an overall higher processing speed.

Contrary to earlier behavioral studies, increased priming effects of the N400 latency in patients with psychotic disorder have been rarely reported (Kiang et al., 2008; Kreher et al., 2008; Mathalon et al., 2010; Nestor et al., 1997). However, there is one study of Spitzer et al. (1997) reporting similar indirect priming effects of the N400 latency in patients with psychotic disorder, with faster N400 latencies in the indirect condition compared to the unrelated condition in patients, but not in the control group (Spitzer et al., 1997). Together with the results from the current study, this possibly indicates an abnormal spreading of activation in the semantic network system in patients with psychotic disorder.

We could not replicate an indirect priming N400 latency effect in the control group at short SOA, which was demonstrated earlier (Weisbrod et al., 1999). Possibly, control subjects process indirectly related targets as unrelated, whereas patients exhibit a further spreading of activation between these prime-target relations. At longer SOA, all groups showed an indirect priming effect of the N400 latency, suggesting that the control and the sibling group had 'caught up' with the patients, in spreading activation to more remote associates (Kreher et al., 2008).

Contrary to the initial hypothesis, no significant between-group differences in associative and indirect priming of the N400 amplitude were found. One reason for this lack of N400 amplitude priming effect might be that the use of the lexical decision task elicited strategic semantic processes (i.e., linking the meaning of the prime word to the target word), even under automatic experimental conditions of the short SOA of $250 \mathrm{~ms}$ (Kuperberg, 2010). The possible influence of strategic semantic processes was demonstrated in a study by
Kreher et al. (2010), in which an implicit semantic monitoring and an explicit semantic matching task (both with a short SOA of $350 \mathrm{~ms}$ and identical word stimuli) was used in the same group of patients with schizophrenia. In the implicit task, an increased direct and indirect N400 amplitude priming effect was found in patients with a higher score of thought disorder compared with healthy controls. In contrast, when patients with schizophrenia were asked to judge explicitly the semantic relationship between prime and targets, they showed abnormally reduced direct and indirect N400 priming effects compared to controls (Kreher et al., 2010). Therefore, it is possible that the explicit lexical decision task which was used in the present study, leads to more controlled processing (even under automatic experimental conditions of short SOA), which possibly explains the lack of indirect N400 amplitude priming effect. A replication of the current study design including an implicit task may clarify this issue.

The result of increased N400 latency effect in patients with psychosis might be related to inappropriate timing processes of neural activity within the semantic network which is possibly related to a further spread of activation to associations which are further away in the semantic network, instead of a faster spreading activation which can be elicited with directly associated targets. This is in line with previous studies, supporting hyper-priming for indirect associates in the spreading activation model in psychosis (Kreher et al., 2008; Moritz et al., 2001b, 2002; Spitzer, 1997; Spitzer et al., 1993, 1997). However, an indirect priming effect of the N400 amplitude across all participants and, most notably, an increase in this effect in patients with psychotic disorder was not observed. Therefore, whether or not the increased indirect N400 latency effect in the patient group, which was observed in the present study, really reflects enhanced spreading activation processes remains to be clarified in future research because the majority of the literature reports invariant N400 latencies and the functional meaning of the N400 latency is less well understood (Kutas and Federmeier, 2011).

By comparing the sibling and the control group, a trend towards a Group $\times$ Condition interaction of the indirect priming N400 latency at short SOA was found. However, by investigating indirect priming in the sibling group, the main effect was not significant. This lack of effect is possibly due to an insufficient sample size and has to be replicated with larger groups. Indeed, inspection of the data revealed that the direction of indirect priming of the N400 latency in siblings was similar to the patient group and in clear contrast to the control group (Fig. 3). However, because it lacks statistical support, caution is required in interpreting this effect. The most conservative conclusion therefore is that on the basis of the current findings, an abnormal spreading activation of the semantic network system does not represent trait familial liability to psychotic disorder.

The results of the present study extend previous findings in several ways. First, the study was designed to control for the impact of the type of the semantic association (by using associative prime-target relations only) and SOA (to assess the time course of automatic to more controlled processes of semantic priming by investigating a possible latency shift of the semantic priming effect with an increase in SOA), thus we can assume that the results were not influenced by these factors. Second, even though there was only a trend towards a Group $\times$ Condition interaction of the indirect priming N400 latency effect, without a significant main effect of indirect priming in the sibling group, the direction of indirect priming in siblings was similar to the patient group. This can be seen as a preliminary additional support for the results in the patient group, given that siblings have a higher than average risk of developing the disorder. This corroborates the findings in the patients, as the effect in siblings is free of confounding effects of antipsychotic medication and other illness-related factors. Third, an increased indirect priming N400 latency effect was also found in patients with psychotic disorder without selecting only patients with FTD, which was previously found to enlarge and reveal 
priming effects in patients, both at the behavioral (Chenery et al., 2004; Moritz et al., 2001a; Spitzer et al., 1993) and at the neural level (Kreher et al., 2008; Weisbrod et al., 1998). A relatively short length of illness (LOI) in the previous study, not exceeding 10 years, could be a possible reason for the enlarged priming effect in patients, as it has been shown that priming effects decrease with length of illness (Maher et al., 1996).

The results of the present study must be interpreted in the context of several methodological issues. Siblings and controls were screened for psychotic and affective disorders and were excluded if they had a lifetime history of psychotic disorder. In the present study, seven of the siblings met criteria for a major depressive disorder (five had a single episode in full remission and two had recurrent episodes in partial remission) that could have biased the results of the sibling group. However, previous studies have observed normal N400 effects in patients with major depressive disorders and dysthymia (Deldin et al., 2006; Iakimova et al., 2009).

The results of the correlational analysis in patients with psychotic disorder showed that higher formal thought disorder scores were related to slower indirect priming of the N400 latency at long SOA. However, because the overall results of the correlational analysis in patients with psychotic disorder showed no large or consistent associations between the $\mathrm{N} 400$ (associative priming or indirect priming) and the formal thought disorder scale, an interpretation of the results is less meaningful. Possibly, the level of symptoms of disorganization may have been to low in this sample.

The group by condition interaction of the three groups was just short of statistical significance $(p=0.77)$ and the further analyses were a follow-up of this non-significant result. This indicates that the exploration of this effect in the separate groups should be interpreted with caution. Accordingly, the finding of the increased indirect priming effect of the $\mathrm{N} 400$ (short SOA) in patients with psychotic disorder compared to the healthy control group is only preliminary and a replication of the study is essential.

At the time of testing, almost all patients were on antipsychotic medication, which may have influenced the magnitude of the observed differences in N400 latency in the indirect priming condition between controls and patients. However, this effect in siblings was in the same direction (albeit not statistically conclusive), suggesting that antipsychotic medication cannot fully explain the observed between-group difference.

The sample size of the groups was relatively small which could have influenced the results. However, several studies showed significant priming effects with comparable sample sizes in healthy controls and in patients with psychotic disorder (Kreher et al., 2008; Mathalon et al., 2002), suggesting that a lack of power is less likely to have influenced the results.

\section{Acknowledgments}

This study was supported in part by GROUP (Genetic Risk and Outcome of Psychosis) Maastricht, and funded in part by the European Seventh Framework Program (EU-GEI consortium). Lydia Krabbendam was supported by a VIDI grant (\# 452-07-007) from the Netherlands Organization of Scientific Research. Niels O. Schiller was supported by a VICI grant (\# 453-02-006) from the Netherlands Organization of Scientific Research.

\section{References}

Alario, F.X., Segui, J., Ferrand, L., 2000. Semantic and associative priming in picture naming. The Quarterly Journal of Experimental Psychology. A 53 (3), 741-764.

Andreasen, N.C., Flaum, M., Arndt, S., 1992. The Comprehensive Assessment of Symptoms and History (CASH). An instrument for assessing diagnosis and psychopathology. Archives of General Psychiatry 49 (8), 615-623.

Baayen, R.H., Piepenbrock, R., Gulikers, L. (Eds.), 1995. The CELEX Lexical Database, Linguistic Data Consortium. University of Pennsylvania, Philadelphia.
Barch, D.M., Cohen, J.D., Servan-Schreiber, D., Steingard, S., Steinhauer, S.S., van Kammen, D.P., 1996. Semantic priming in schizophrenia: an examination of spreading activation using word pronunciation and multiple SOAs. Journal of Abnormal Psychology 105 (4), 592-601.

Bleuler, E., 1950. Dementia Praecox or the Group of Schizophrenias. (Translated by J. Zinkin) International Universities Press, New York.

Chenery, H.J., Copland, D.A., McGrath, J., Savage, G., 2004. Maintaining and updating semantic context in schizophrenia: an investigation of the effects of multiple remote primes. Psychiatry Research 126 (3), 241-252.

Collins, A.M., Loftus, E.F., 1975. A spreading activation theory of semantic processing. Psychology Review 82, 407-428.

Condray, R., Siegle, G.J., Cohen, J.D., van Kammen, D.P., Steinhauer, S.R., 2003. Automatic activation of the semantic network in schizophrenia: evidence from event-related brain potentials. Biological Psychiatry 54 (11), 1134-1148.

Cutting, J.C., Ferreira, V.S., 1999. Semantic and phonological information flow in the production lexicon. Journal of Experimental Psychology: Learning, Memory, and Cognition 25 (2), 318-344.

de Groot, A.M.B., de Bil, J.M., 1987. Nederlandse Woordassociatienormen Met Reactietijden: 100 Woordassociaties Op 240 Substantieven, 80 Adjectieven En 80 Verba: Swets \& Zeitlinger.

Deldin, P., Keller, J., Casas, B.R., Best, J., Gergen, J., Miller, G.A., 2006. Normal N400 in mood disorders. Biological Psychology 71 (1), 74-79.

Docherty, N.M., DeRosa, M., Andreasen, N.C., 1996. Communication disturbances in schizophrenia and mania. Archives of General Psychiatry 53 (4), 358-364.

Federmeier, K.D., Kutas, M., 1999. Right words and left words: electrophysiological evidence for hemispheric differences in meaning processing. Brain Research. Cognitive Brain Research 8 (3), 373-392.

Gratton, G., Coles, M.G., Donchin, E., 1983. A new method for off-line removal of ocular artifact. Electroencephalography and Clinical Neurophysiology 55 (4), 468-484.

Greenhouse, S.W., Geisser, S., 1959. On methods in the analysis of profile data. Psychometrika 24, 95-112.

Guerra, S., Ibáñez, A., Martín, M., Bobes, M.A., Reyes, A., Mendoza, R., Bravo, T., Domínguez, M., Sosa, M.V., 2009. N400 deficits from semantic matching of pictures in probands and first-degree relatives from multiplex schizophrenia families. Brain and Cognition 70 (2), 221-230.

Iakimova, G., Passerieux, C., Foynard, M., Fiori, N., Besche, C., Laurent, J.P., Hardy-Baylé, M.C., 2009. Behavioral measures and event-related potentials reveal different aspects of sentence processing and comprehension in patients with major depression. Journal of Affective Disorders 113 (1-2), 188-194.

Kerns, J.G., Berenbaum, H., 2000. Aberrant semantic and affective processing in people at risk for psychosis. Journal of Abnormal Psychology 109 (4), 728-732.

Kiang, M., Kutas, M., 2005. Association of schizotypy with semantic processing differences: an event-related brain potential study. Schizophrenia Research 77 (2-3), 329-342.

Kiang, M., Kutas, M., Light, G.A., Braff, D.L., 2008. An event-related brain potential study of direct and indirect semantic priming in schizophrenia. The American Journal of Psychiatry 165 (1), 74-81.

Kiefer, M., Weisbrod, M., Kern, I., Maier, S., Spitzer, M., 1998. Right hemisphere activation during indirect semantic priming: evidence from event-related potentials. Brain and Language 64 (3), 377-408.

Kimble, M., Lyons, M., O'Donnell, B., Nestor, P., Niznikiewicz, M., Toomey, R., 2000. The effect of family status and schizotypy on electrophysiologic measures of attention and semantic processing. Biological Psychiatry 47 (5), 402-412.

Kreher, D.A., Holcomb, P.J., Kuperberg, G.R., 2006. An electrophysiological investigation of indirect semantic priming. Psychophysiology 43 (6), 550-563.

Kreher, D.A., Holcomb, P.J., Goff, D., Kuperberg, G.R., 2008. Neural evidence for faster and further automatic spreading activation in schizophrenic thought disorder. Schizophrenia Bulletin 34 (3), 473-482.

Kreher, D.A., Goff, D., Kuperberg, G.R., 2010. Why all the confusion? Experimental task explains discrepant semantic priming effects in schizophrenia under "automatic" conditions: evidence from event-related potentials. Schizophrenia Research 111 (1-3), 147-181.

Kumar, N., Debruille, J.B., 2004. Semantics and N400: insights for schizophrenia. Journal of Psychiatry \& Neuroscience 29 (2), 89-98.

Kuperberg, G.R., 2010. Language in schizophrenia part 1: an introduction. Language Linguistic Compass 4 (8), 576-589.

Kutas, M., Federmeier, K.D., 2011. Thirty years and counting: finding meaning in the N400 component of the event-related brain potential (ERP). Annual Review of Psychology 62, 621-647.

Kutas, M., Hillyard, S.A., 1980. Reading senseless sentences: brain potentials reflect semantic incongruity. Science 207 (4427), 203-205.

La Heij, W., Dirkx, J., Kramer, P., 1990. Categorical interference and asscoiative priming in picture naming. British Journal of Psychology 81, 511-525.

Lauteslager, M., Schaap, T., Schievels, D., 1986. Schriftelijke Woordassociatienormen Voor 549 Nederlandse Zelfstandige Naamwoorden: Swets \& Zeitlinger B.V.

Lukoff, D., Nuechterlein, K.H., Ventura, J., 1986. Manual for the Expanded Brief Psychiatric Rating Scale. Schizophrenia Bulletin 12, 594-602.

Luteijn, F., van der Ploeg, F., 1983. Handleiding Groninger Intelligentietest (GIT) (Manual Groningen Intelligence Test). Swets \& Zeitlinger, Lisse, The Netherlands.

Maher, B.A., Manschreck, T.C., Redmond, D., Beaudette, S., 1996. Length of illness and the gradient from positive to negative semantic priming in schizophrenic patients. Schizophrenia Research 22 (2), 127-132.

Manschreck, T.C., Maher, B.A., Milavetz, J.J., Ames, D., Weisstein, C.C., Schneyer, M.L., 1988. Semantic priming in thought disordered schizophrenic patients. Schizophrenia Research 1 (1), 61-66. 
Mathalon, D.H., Faustman, W.O., Ford, J.M., 2002. N400 and automatic semantic processing abnormalities in patients with schizophrenia. Archives of General Psychiatry 5 (7), 641-648.

Mathalon, D.H., Roach, B.J., Ford, J.M., 2010. Automatic semantic priming abnormalities in schizophrenia. International Journal of Psychophysiology 75 (2), 157-166.

Minzenberg, M.J., Ober, B.A., Vinogradov, S., 2002. Semantic priming in schizophrenia: a review and synthesis. Journal of the International Neuropsychological Society 8 (5), 699-720.

Morgan, C., Bedford, N., Rossell, S.L., 2006. Evidence of semantic disorganisation using semantic priming in individuals with high schizotypy. Schizophrenia Research 84 (2-3), 272-280.

Moritz, S., Andresen, B., Domin, F., Martin, T., Probsthein, E., Kretschmer, G., Krausz, M., Naber, D., Spitzer, M., 1999. Increased automatic spreading activation in healthy subjects with elevated scores in a scale assessing schizophrenic language disturbances. Psychological Medicine 29 (1), 161-170.

Moritz, S., Mersmann, K., Kloss, M., Jacobsen, D., Andresen, B., Krausz, M., Pawlik, K. Naber, D., 2001a. Enhanced semantic priming in thought-disordered schizophrenic patients using a word pronunciation task. Schizophrenia Research 48 (2-3), 301-305.

Moritz, S., Mersmann, K., Kloss, M., Jacobsen, D., Wilke, U., Andresen, B., Naber, D., Pawlik, K., 2001b. 'Hyper-priming' in thought-disordered schizophrenic patients. Psychological Medicine 31 (2), 221-229.

Moritz, S., Woodward, T.S., Kuppers, D., Lausen, A., Schickel, M., 2002. Increased automatic spreading of activation in thought-disordered schizophrenic patients. Schizophrenia Research 59 (2-3), 181-186.

Nestor, P.G., Kimble, M.O., O'Donnell, B.F., Smith, L., Niznikiewicz, M., Shenton, M.E., McCarley, R.W., 1997. Aberrant semantic activation in schizophrenia: a neurophysiological study. The American Journal of Psychiatry 154 (5), 640-646.

Nestor, P.G., Valdman, O., Niznikiewicz, M., Spencer, K., McCarley, R.W., Shenton, M.E., 2006. Word priming in schizophrenia: associational and semantic influences. Schizophrenia Research 82 (2-3), 139-142.

NeurobehaviouralSystems, 2006. Presentation. Albany.

Niznikiewicz, M.A., Voglmaier, M., Shenton, M.E., Seidman, L.J., Dickey, C.C., Rhoads, R. Teh, E., McCarley, R.W., 1999. Electrophysiological correlates of language processing in schizotypal personality disorder. The American Journal of Psychiatry 156 (7), 1052-1058.
Niznikiewicz, M.A., Friedman, M., Shenton, M.E., Voglmaier, M., Nestor, P.G., Frumin, M., Seidman, L., Sutton, J., McCarley, R.W., 2004. Processing sentence context in women with schizotypal personality disorder: an ERP study. Psychophysiology 41 (3), 367-371.

Ober, B.A., Vinogradov, S., Shenaut, G.K., 1997. Automatic versus controlled semantic priming in schizophrenia. Neuropsychology 11 (4), 506-513.

Smeets, R.M.W., Dingemans, P.M.A.J., 1993. Composite International Diagnostic Interview (CIDI). World Health Organisation, Amsterdam/Geneva.

Spitzer, M., 1997. A cognitive neuroscience view of schizophrenic thought disorder. Schizophrenia Bulletin 23 (1), 29-50.

Spitzer, M., Braun, U., Hermle, L., Maier, S., 1993. Associative semantic network dysfunction in thought-disordered schizophrenic patients: direct evidence from indirect semantic priming. Biological Psychiatry 34, 864-877.

Spitzer, M., Weisker, I., Winter, M., Maier, S., Hermle, L., Maher, B.A., 1994. Semantic and phonological priming in schizophrenia. Journal of Abnormal Psychology 103 (3), 485-494.

Spitzer, M., Weisbrod, M., Winkler, S., Maier, S., 1997. Event-related potentials in semantic speech processing by schizophrenic patients. Nervenarzt 68 (3), 212-225.

SPSS, 2008. SPSS for Windows Rel. 16.0.2. SPSS Inc., Chicago.

Starreveld, P.A., La Heij, W., 1996. Time-course analysis of semantic and orthographic context effects in picture naming. Journal of Experimental Psychology 22 (4) 896-918.

Vinogradov, S., Ober, B.A., Shenaut, G.K., 1992. Semantic priming of word pronunciation and lexical decision in schizophrenia. Schizophrenia Research 8 (2), 171-181.

Wechsler, D., 1997. Wechsler Adult Intelligence Scale, 3rd ed. Harcourt Assessment, San Antonio, TX.

Weisbrod, M., Maier, S., Harig, S., Himmelsbach, U., Spitzer, M., 1998. Lateralised semantic and indirect semantic priming effects in people with schizophrenia. The British Journal of Psychiatry 172, 142-146.

Weisbrod, M., Kiefer, M., Winkler, S., Maier, S., Hill, H., Roesch-Ely, D., Spitzer, M., 1999 Electrophysiological correlates of direct versus indirect semantic priming in normal volunteers. Brain Research. Cognitive Brain Research 8 (3), 289-298.

Zeelenberg, R., Pecher, D., 2002. False memories and lexical decision: even twelve primes do not cause long-term semantic priming. Acta Psychologica 109 (3), 269-284. 